\title{
Mariagrazia Margarito (ed.), Cahier de lecture(s) de l'affiche publicitaire
}

\section{Elettra Bordino Zorzi}

\section{(2) OpenEdition}

1 Journals

\section{Édition électronique}

URL : http://journals.openedition.org/studifrancesi/36931

DOI : 10.4000/studifrancesi.36931

ISSN : 2421-5856

Éditeur

Rosenberg \& Sellier

\section{Édition imprimée}

Date de publication : 1 juillet 2005

Pagination : 217-218

ISSN : 0039-2944

\section{Référence électronique}

Elettra Bordino Zorzi, « Mariagrazia Margarito (ed.), Cahier de lecture(s) de l'affiche publicitaire », Studi Francesi [En ligne], 145 (XLIX | I) | 2005, mis en ligne le 30 novembre 2015, consulté le 19 avril 2021. URL : http://journals.openedition.org/studifrancesi/36931 ; DOI : https://doi.org/10.4000/ studifrancesi.36931

Ce document a été généré automatiquement le 19 avril 2021.

\section{(c)}

Studi Francesi è distribuita con Licenza Creative Commons Attribuzione - Non commerciale - Non opere derivate 4.0 Internazionale. 


\title{
Mariagrazia Margarito (ed.), Cahier de lecture(s) de l'affiche publicitaire
}

\author{
Elettra Bordino Zorzi
}

\section{RÉFÉRENCE}

MARIAGRAZIA MARGARITO (ed.), Cahier de lecture(s) de l'affiche publicitaire, Fasano, Schena editore - Presses de l’Université de Paris-Sorbonne, 2003, pp. 157.

1 Au coeur du vaste univers bibliographique concernant la publicité, ce livre est né affirme Mariagrazia Margarito dans sa Présentation-introduction (pp. 7-12) - sous une triple étoile: comme le fruit d'un long travail de recherche, comme un signe de gratitude envers tous ceux, en particulier les étudiants, qui y ont participé, comme un lieu de propositions didactiques sur support électronique. Le CD-Rom accompagnant le volume présente, en effet, cent cinquante affiches organisées et décodées suivant des parcours interprétatifs de dérivation sémiologique (publicité de dénotation et de connotation, rapport langue/icône, code du regard, codes de lecture, rhétorique dans l'image). Si, inévitablement, l'aspect visuel prend ici le dessus, c'est au contraire le message linguistique qui est privilégié dans les trois essais dont se compose l'ouvrage en papier.

2 Paola PAISSA (Enthymèmes et autres mécanismes déductifs dans un corpus de slogans publicitaires français, pp. 13-38) s'intéresse à la logique, ou plus exactement à la pseudologique dont tirent profit quelques annonces figurant dans des magazines des années 1999-2000. De ce corpus il résulte que l'argumentation publicitaire tend à se construire sur le modèle ternaire de l'enthymème, syllogisme aux prémisses uniquement probables, ou à épouser le mouvement binaire qu'engendre tantôt la sollicitation directe du co-énonciateur, en particulier par le biais de l'interrogation oratoire, tantôt la focalisation sur deux arguments, qu'elle soit explicite (symétrie, antithèse) ou implicite (métonymie, euphémisme, métaphore), ce qui comporte un changement 
progressif de régime (de la déduction à l'imagination) et une marge plus ample de liberté interprétative.

3 Nicole WERLY (Quand les marchands sont chassés du temple. La gestion discursive des émotions dans la publicité humanitaire, pp. 39-90) analyse les procédés linguistiques, rhétoriques et énonciatifs mis en place dans deux cents publicités humanitaires tirées de périodiques français (années 1998-2002). Dans ces textes non commerciaux, la crédibilité est certes un réquisit indispensable, les faits évoqués devant s'imposer comme vrais et non pas tout simplement comme vraisemblables ou souhaitables, mais l'essentiel du dispositif argumentatif gravite autour de la fabrication des émotions. Plus souvent suscitées (pitié, indignation, honte, douleur, joie, admiration) ou réfutées (méfiance, indifférence) que dites (presque exclusivement la souffrance des victimes), celles-ci sont construites au moyen d'un lexique affectif-axiologique, d'une topique spécifique et d'un arsenal de figures stylistiques et de locutions figées partiellement retravaillées. Corrélativement, sur le plan des instances discursives, le pathos d'un auditoire imaginé sensible aux valeurs défendues complète et couronne l'ethos d'un orateur représenté comme honnête, fiable, efficace. Ces deux figures sont à ce point solidaires que le «nous» énonciatif et le «vous» vocatif finissent par fusionner dans un «nous» émotionnel qui scelle le pacte d'intervention.

Enfin Françoise RIGAT (L'oeuvre d'art dans l'image publicitaire: effets interprétatifs, pp. 91-138) s'interroge sur la reproduction d'œuvres d'art, surtout picturales, dans des annonces publicitaires récentes (1999-2002). Bien que ces images célèbres subissent des manipulations diverses, elles ont l'avantage d'être immédiatement reconnaissables et d'exercer une grande séduction sur le public. Leur fonction, par rapport à la composante textuelle, est soit d'illustration soit d'élucidation: dans le premier cas, la peinture totalement ou partiellement citée est destinée à représenter un concept exprimé dans le texte, à moins qu'il ne s'agisse d'une simple homonymie; dans le second cas, le visuel bat en brèche le verbal et fait pleinement sens. Quant à la visée finale, loin de se borner à l'aspect esthétique, elle empiète sur le social car l'œuvre d'art en publicité active des références culturelles et identitaires que le destinataire est censé partager. 